\title{
Clinical Pathways as Instruments for Risk and Cost Management in Hospitals - A Discussion Paper
}

\author{
Tobias Romeyke (Corresponding author) \\ Dept. of Public Health, Information Systems and Health Technology Assessment \\ UMIT - University for Health Sciences, Medical Informatics and Technology \\ Opernring 5, A-1010 Vienna, Austria \\ E-mail: tobias.romeyke@umit.at \\ Harald Stummer \\ Dept. of Public Health, Information Systems and Health Technology Assessment \\ UMIT - University for Health Sciences, Medical Informatics and Technology \\ Opernring 5, A-1010 Vienna, Austria
}

Received: December 7, 2011 Accepted: December 21, 2011 Published: March 1, 2012

doi:10.5539/gjhs.v4n2p50 URL: http://dx.doi.org/10.5539/gjhs.v4n2p50

\begin{abstract}
Introduction: The distinctive characteristics of the German health system are medical progress and financial pressure - and this is especially true of the hospitals. These challenges must be met by strategic management instruments for quality assurance, and by reducing costs. Purpose: This article presents the instrument "clinical pathway" (also known as "clinical treatment pathway") and describes the possibilities it offers, both for quality assurance and risk management, and for cost reduction. The clinical pathway presented here will be that for "multimodal pain therapy", as used in the context of acute inpatient care in Germany. Methods: A general presentation of the risks in hospital is followed by consideration of the risks associated with core processes. A comprehensive total cost analysis is performed for those patients who meet the pathway entry criteria and who fulfil the requirements for the structure of care provided within multimodal pain therapy. Discussion and Conclusion: Multimodal pain therapy places high demands on the structural, procedural and outcome quality of the medical, nursing and therapeutic services provided, and these demands are reflected in high costs for the provision of this care. The treatment process involves many different professional groups. These complex interfaces can potentially generate risks, which can lead to the possibility of legal liability. A clinical pathway must structure the core process and then combine elements of quality assurance in order to optimise patient care and minimise risk. The examination of costs reveals significant potential savings (patients with clinical pathway: EUR $3086 \pm 212$; patients without clinical pathway: EUR 3774 \pm 460 ; Mann-Whitney $U$ test; $p<0.001$ ). For the managers of a hospital, the clinical pathway represents a strategic management instrument that can serve for continual cost control and cost reduction, and can contribute in the form of quality assurance towards a transparent provision of services.
\end{abstract}

Keywords: Clinical pathway, Quality management, Multimodal pain therapy, Risk management, Cost efficiency, Total cost

\section{Introduction}

\subsection{Clinical Pathways}

Health care world-wide presents a challenge regarding its organisation and the efficient allocation of resources. This challenge is increasing as a result of continual progress in the field of medicine and sustained demographic development. The greatest costs in the health system are generated by hospital treatment. The costs for the almost 2,100 hospitals in Germany increased by $6.1 \%$ during the year 2009 to reach a total of 77.1 billion euros (Statistisches Bundesamt "Federal Statistics Office", 2011). 
More and more hospitals in Germany are striving to restructure their procedures for providing services in order to generate potential for reducing costs. They are aiming simultaneously to optimise the quality of their processes and outcomes.

To this end, clinical pathways will become increasingly important in the context of case tariff fees as a part of the International Statistical Classification of Diseases and Related Health Problems (ICD) for inpatient hospital services. These pathways will contribute towards shortening the period of hospitalisation (Hommel et al., 2008; Ishiguro et al., 2008), reducing costs (Verdú et al., 2009; Barbieri et al., 2009; Rook 1998; Velasco et al., 1996) and increasing the quality of the services provided (Schwarzbach et al., 2010; Andriessen et al., 2009; Feuth \& Claes, 2008). A generally valid definition of "clinical pathway" exists neither in the USA, nor in Australia, nor in Europe. Hindle (1997) defines the clinical pathway as a document describing the services provided in the multidisciplinary treatment of a particular type of patient, which enables comments to be made about deviations from the norm for the purpose of evaluation and improvement.

The development of a clinical path must relate to indications or procedures and, in order to achieve greater efficiency and quality benefits, must cover the patients and cases focused on by the hospital and therefore occurring most frequently. Patients, doctors, nurses and therapeutic personnel must all be involved in the development of a clinical pathway in order to integrate indication-related, evidence-based and best-practice procedures as requirements in the clinical pathway. The present work examines in greater detail the contribution of a clinical pathway with regard to aspects of risk management, quality assurance and cost efficiency for multimodal pain therapy.

\subsection{Multimodal Pain Therapy in Germany (OPS 8-918)}

Physical pain is not the only symptom suffered by patients subject to chronic pain; at the psychological level, chronic pain is accompanied by a wide variety of cognitive and emotional factors. Patients suffering from chronic pain frequently suffer from accompanying diseases which can be manifested, for example, in the form of states of anxiety and panic, despair, depression and lability (Banks \& Kerns 1996; McWilliams et al., 2003). Most chronic pain patients withdraw from their social environment, show less and less interest in social contacts and activities, and become involved in interpersonal conflicts within their family, or among their friends, or colleagues at work (Cowan et al., 1998).

The Deutsche Gesellschaft zum Studium des Schmerzes (DGSS) (“German Society for the Study of Pain") defines multimodal pain therapy as the "interdisciplinary treatment of patients with chronic pain syndrome in such a way that the different therapies, given simultaneously with mutual coordination of their content, chronology and procedure, are integrated with the different somatic, physical, psychological, occupational and psychotherapeutic methods according to a predefined therapy plan with an identical therapeutic target agreed among the therapists".

Multimodal pain therapy is listed as Procedure 8-918 in the Operationen- und Prozedurenschlüssel (OPS) ("Operations and Procedures Code") in the versions published by the Deutschen Institut für Medizinische Dokumentation ("German Institute for Medical Documentation") at the behest of the Bundesministerium für Gesundheit ("Federal Ministry of Health") pursuant to $\S \S 295$ and $301 S G B$ V ("Social Code"). The acceptance and further development of inpatient multimodal pain therapy within the German case tariff fee system $(G-D R G)$ result from the efforts of a number of professional associations, which include the Deutsche Gesellschaft zum Studium des Schmerzes (DGSS) ("German Society for the Study of Pain", the Berufsverband Deutscher Anästhesisten (BDA) ("Professional Association of German Anaesthetists", the Gesellschaft für Anästhesiologie und Intensivmedizin (DGAI) ("Association for Anaesthesiology and Intensive Medicine"), and the Deutsche Interdisziplinäre Vereinigung für Schmerztherapie (DIVS) ("German Interdisciplinary Association for Pain Therapy"). The multimodal pain therapy is used in specialized clinics in Germany.

Multimodal pain therapy in accordance with OPS 8-918 places high demands on the structural, procedural and outcome quality of the provision of inpatient services. The OPS stipulates an interdisciplinary team whose members have specialised in different fields. The therapy manager must be a specialist with an additional qualification in "special pain therapy". The term special pain therapy requires special knowledge in the areas of conservative medical (eg, internal medicine, neurology, etc.), operative medicine (surgery, neurosurgery, orthopedics, etc.) and conservative and interventional medicine (anesthesiology, radiation, etc.). Particulary basic knowledge about the pathogenesis, diagnosis and therapy, bio-psycho-social history of pain, mental disorders with pain and psychosomatic interactions in chronic pain states further expertise in neuropathic pain, pain with vascular disease, pain in visceral disease, cancer pain, pain in children and adolescents, muscle pain, back pain, joint disorders. The structural requirements for performing multimodal pain therapy also correspond with the requirements of evidence-based provision of services. According to this, indication-related behavioural therapy 
(Chou \& Huffman 2007; Gatchel \& Rollings, 2008), occupational therapy with movement-therapy approaches (Hayden et al., 2005) and ergotherapeutic methods (Williams et al., 2007) must be integrated in the therapy plan. Ergotherapeutic methods include "joint protection measures", "learning of substitute functions", "improving the mobility and locomotion", "hand therapy", "training of life skills".

Depending on the clinical picture, physiotherapeutic measures (Gross et al., 2004), art (Sexton-Radek, 1999) and music therapy (Good et al., 2002; Tan et al., 2010), therapy for workplace training, sensomotoric training, and medical training therapy (Valim et al., 2003) must be prescribed by the medical staff. Therapies for worplace training include for example correct posture, stretching and relaxation exercises at the PC workstation.

The prescribed treatment methods are used depending on the clinical picture. The methods of conventional medicine are transformed into an integrated and holistic approach of therapy.

\section{Methods}

\subsection{Risks in the Provision of Inpatient Services}

As a result of legal requirements and the fact that human life is at the focus of the services provided, the risks prevalent in a hospital are particularly diverse. Starting from the general risks in the hospital, attention must be directed towards the procedure-related risks, and approaches to solutions must be worked out for multimodal pain therapy.

\subsection{Pathway Entry Criteria}

Examination of the pathway entry criteria (Fig. 1) is an integral part of structured admission management, based on which the therapeutic objectives are defined and the pathway sequence is oriented; this, in turn, demands complex interface management.

\subsection{Structural Requirements and Provision of Services}

The code for multimodal pain therapy stipulates a minimum of seven days interdisciplinary treatment (by legislation) of patients with chronic pain conditions (including tumour pain) with involvement of at least two specialist fields (of which one must be a psychiatric, psychosomatic or psychological discipline). In addition, at least three of the following active therapeutic methods must be used simultaneously: psychotherapy, physiotherapy, relaxation techniques, ergotherapy, medical training therapy, sensomotoric training, workplace training, artistic therapy (art or music therapy) or other kinds of occupational therapy. The therapy sessions last an average of 30 minutes. The code also includes an evaluation of the progression of the treatment by means of a standardised therapeutic assessment, a daily doctor's visit or team discussion, and a weekly interdisciplinary team meeting. In group therapy, the size of the group is limited to a maximum of 8 people. Use of this code requires that the responsible doctor has the additional qualification "special pain therapy" (OPS 8-918; The operations and procedure code (OPS) is published by DIMDI ["German Institute for Medical Documentation"] on behalf of the Federal Ministry of Health).

\subsection{Costs Analysis}

Based on the path entry criteria (Section 2.2.) and the structural requirements for providing services (Section 2.3.), an analysis was performed of the total costs incurred by 65 subjects who received inpatient treatment in accordance with the requirements of multimodal pain therapy. The costs data were acquired by means of cost type accounting, cost centre accounting by means of cost-centre related cost distribution, and differential in-house performance accounting which localises the places at which costs are incurred. As the final stage of the cost accounting, cost unit accounting identifies the reasons for the costs incurred and allocates the final cost centres to the individual beneficiaries of services.

\section{Discussion and Conclusion}

\subsection{Path-Indicated Quality Assurance and Risk Minimisation}

Hospitals are characterised by complex interfaces.

The risks to which a hospital is exposed are extremely complex, at the level of both the control processes and the support processes, and care is essential when examining them (Fig. 3). Control processes in the hospital include strategic management and controlling, and the requirements for internal and external quality assurance. Support processes include financial controlling, materials management and pharmaceutical services.

German legislation ensures greater safeguards for stake- and shareholders in that it defines appropriate standards for issuing early warnings of risks that could lead to the demise of the enterprise. This includes the Gesetz zur Kontrolle und Transparenz im Unternehmensbereich (KonTraG) ("Corporate Sector Supervision and 
Transparency Act"). The core of the $\operatorname{KonTraG}$ is a regulation that obligates the company management to implement a risk early-warning system and which extends the liability of the board of directors, supervisory board and auditors. Against a background of increasing liability claims for errors in treatment, risk management also occupies an important position at the core process level (diagnosis and therapy).

According to Führing and Gausmann (2004), the aims of clinical risk management are the continual improvement of treatment quality and patient safety, and defence of the hospital against unjustified claims against the institution made by patients (Führing \& Gausmann, 2004).

Studies have shown that the number of cases in which patients suffer harm while receiving treatment is considerable (Thomas et al., 2000; Weingart et al., 2000; Baker et al., 2004). An analysis of 1014 treatment cases selected at random in two English hospitals revealed that $10.8 \%$ of the patients suffered unintentional impairment to their health; $46 \%$ of the errors could potentially have been avoided (Vincent \& Neale, 2001). Organisational deficiencies are especially prevalent as the (co-)origin of accusations of error (Hansis \& Hansis, 1999). Inadequate documentation and education, insufficient communication between members of the individual professions and failure to comply with departmental operating procedures can also contribute to the poor progression of treatment, and to accusations of error.

Risk management and quality management are inextricably connected and, as an integrated system (Roeder et al., 2007), pursue the objective of minimising the risks for patients, staff and the organisation, and maximising the quality of the care provided (Bernsmann et al., 2002).

Interdisciplinary diagnosis and treatment of pain involves many different professions. Complex interfaces can generate potential risks, which may lead to possible legal liability. In addition to the significance of possible liability, the occurrence of liability cases can result in patients' dissatisfaction becoming publicly known which, in turn, can result in fewer patients and lower returns. Risk potentials must be identified in order to prevent liability cases. In the treatment progression of multimodal pain therapy, a clinical pathway stipulates standardisation of the multidisciplinary processes and services, enabling quality fluctuations to be reduced and treatment risks to be minimised (Schlüter et al., 2006). Integration in the clinical pathway of all staff involved in the treatment process, and coordination of the clinical progression offers the possibility of overcoming interface problems. Clinical pathway OPS 8-918 stipulates an interdisciplinary pain anamnesis by the doctors, nurses and therapists (Fig.2), which includes not only a complete description of the patient's past pain, but also of his or her present symptoms. In addition, possible care-relevant secondary diagnoses are made by the nursing staff (Fig.4) and evaluated and dealt with jointly with the other staff involved in the treatment process. This also complies with the principle of a holistic therapy of the patient's pain.

The specialist medical evaluation of the pain screening and the other examinations define the type and sequence of the subsequent diagnoses and the medication and therapeutic regimen. Both the generation of findings for purposes of quality assurance and risk minimisation, and the monitoring of the therapeutic progression are subject to different score parameters specified according to indication, and these accompany the treatment processes. For example, the clinical pathway for multimodal pain therapy for diseases and disturbances of the musculoskeletal system and connective tissue requires the measurement, several times a day, of the pain intensity by means of the visual analogue scale (VAS) (Winlkelmann \& Schreiber, 1997), whereas the functional capacity of patients with rheumatic diseases is recorded using the "Hannover Questionnaire" (FFbH) (Kohlmann \& Raspe, 1996). The visual analog scale is a semiquantitive procedure for the subjective measurement of pain intensity. 12 statements by the $\mathrm{FFbH}$ allows to measure the functional capacity at activities of daily living (mobility, personal hygiene, dressing and undressing) which may be affected by problems in the spine. This instrument, according to Kohlmann and Raspe (1996) already light up moderate functional limitations found in back pain patients. On admission, all aspects of pain occurrence, pain sensitivity, social anamnesis, pain intensity, pain character and pain localisation are evaluated using the pain questionnaire of the DGSS ("German Society for the Study of Pain"). For inflammatory rheumatic diseases, the disease activity score (DAS) is used (Cruyssen et al., 2005; Prevoo et al., 1995) (Fig.2). This disease activity score indicates how high the disease activity is and was developed in Europe as an alternative to the ACR (American College of Rheumatology) criteria. Every diagnostic procedure functions as a risk management instrument (drug administration, determination of active and passive therapeutic measures, etc.) and serves at the same time to assure the quality of the process and the outcome.

In addition, all risks that arise in association with drugs administered for specific kinds of treatment and with methods of pain therapy must be recorded and discussed during a patient briefing.

The treatment process is accompanied by complete medical and therapeutic documentation and a variance analysis. The resulting transparency for the different providers of services forms the basis for minimisation of treatment 
risks and poor outcomes, maximisation of internal quality, and compliance with the requirements of quality assurance (Romeyke, 2009).

Figure 5 summarises as a checklist in eleven items the important elements of risk minimisation and quality assurance in pain therapy.

\subsection{Generation of Efficiency Potentials}

In addition to aspects of risk and quality management, active process management should also take cost aspects into account.

All 65 subjects fulfilled the pathway entry criteria described under 2.2., enabling Procedure 8-918 to be coded correctly in accordance with the requirements of the $O P S$.

The mean total costs for the 65 patients amounted to EUR 3467.08 (Fig. 6a and 6b). Patients for whom a clinical pathway (CP) was used incurred significantly lower costs than patients without CP (patients with CP: EUR $3086 \pm 212$; patients without CP: EUR 3774 \pm 460 ; Mann-Whitney U test; $\mathrm{p}<0.001$ ). This difference can be attributed to the clinical pathway requiring pre-defined, structured admission management with integrated pain anamnesis, the standardised use of evidence-based and best-practice measures, and the avoidance of inappropriate prescriptions. A clinical pathway must be designed so as to guarantee efficient allocation of resources in inpatient care.

\subsection{Conclusion}

Hospitals in future will have to cope with the fact that under the terms of a case tariff fee system, more cases will have to be treated with the same, or even a reduced, staffing level. It therefore appears necessary to identify and remove existing deficiencies in how procedures are organised. In the context of operative risk management, this must include the analysis, evaluation and monitoring of risks associated with diagnoses and procedures, with the aim of ensuring risk-free provision of services (Erben \& Romeike, 2003). For the providers of services at the core process level (medical specialists, nursing staff, therapists and non ward-based nursing staff), clinical pathways will simplify the treatment process, and prevent - or at least minimise — risks by means of structured and comprehensive diagnosis and treatment procedures. Clinical pathways serve for quality assurance and make a contribution to ensuring net income from case tariff fees. By means of the indication- and procedure-related progression planning, they serve doctors, nurses and therapists as an instrument for the familiarisation and evaluation of the treatment process.

For the business management of a hospital, the clinical pathway presents a strategic management instrument that also serves as an instrument for continual cost controlling, and can contribute to transparency in the provision of services. Knowledge relevant to quality and to supply planning can be acquired and the range of services can be standardised without neglecting the individual requirements of the patients.

\section{References}

Andriessen, A. E., Polignano, R., \& Abel, M. (2009). Development and implementation of a clinical pathway to improve venous leg ulcer treatment. Wounds: A Compendium of Clinical Research \& Practice (WOUNDS), 21 (5), 127-33 (17 ref).

Baker, G. R., Norton, P. G., Flintoft, V., et al. (2004). The Canadian Adverse Events Study: the incidence of adverse events among hospital patients in Canada. JAMC, 170, 1678-1686. http://dx.doi.org/10.1503/cmaj.10404 98

Banks, S. M., \& Kerns, R. D. (1996). Explaining the high rates of depression in chronic pain: A stress diathesis framework. Psychol Bull, 119, 95-110. http://dx.doi.org/10.1037/0033-2909.119.1.95

Barbieri, A., Vanhaecht, K., Van Herck, P., et al. (2009). Effects of clinical pathways in the joint replacement: a meta-analysis. BMC Medicine, 7 (32), 1-11. http://dx.doi.org/10.1186/1741-7015-7-32

Bernsmann, K., Neumann, M., \& Schleberger, R. (2002). Riskmanagement in der Krankenhauspraxis. Eine Einführung mit Anwendungsbeispielen aus orthopädischen Kliniken. Kohlhammer.

Chou, R., \& Huffman, L. H. (2007). Nonpharmacologic therapies for acute and chronic low back pain: a review of the evidence for an American Pain Society/American College of Physicians clinical practice guideline. Ann Intern Med, 147 (7), 492-504.

Cowan, P., Kelly, N., Pasero, C., et al. (1998). Family manual. A manual for families of person with pain. Rocklin, CA: American Chronic Pain Association. 
Cruyssen, B. C., Looy, S. V., Wyns, B., et al. (2005). DAS28 best reflects the physician's clinical judgment of response to infliximab therapy in rheumatoid arthritis patients: validation of the DAS28 score in patients under infliximab treatment. Arthritis Research \& Therapy, 7, R1063-R1071. http://dx.doi.org/10.1186/ar1787

Erben, R. F., \& Romeike, F. (2003). Risikoreporting mit Unterstützung von Risk-ManagementInformationssystemen (RMIS). In: F. Romeike, \& R. B. Finke, Erfolgsfaktor Risikomanagement, Wiesbaden.

Feuth, S., \& Claes, L. (2008). Introducing clinical pathways as a strategy for improving care. Journal of Integrated Care Pathways, 12 (2), 56-60 (7 ref). http://dx.doi.org/10.1258/jicp.2008.008008

Führing, M., \& Gausmann, P. (2004). Klinisches Risikomanagement im DRG-Kontext Integration von Risiko-Kontrollpunkten in klinische Pfade.

Gatchel, R. J., \& Rollings, K. H. (2008). Evidence-based review of the efficacy of cognitive-behavioral therapy for the treatment of chronic low back pain. Spine J, 8, 40-44.

Good, M., Anderson, G. C., Stanton-Hicks, M., et al. (2002). Relaxation and music reduce pain after gynecologic surgery. Pain Management Nursing, 3 (2), 61-70. http://dx.doi.org/10.1002/nur.20076

Gross, A. R., Hoving, J. L., \& Haynes, T. A. (2004). A cochrane review of manipulation and mobilization for mechanical neck disorders. Spine, 29, 1541-8. http://dx.doi.org/10.1097/01.BRS.0000131218.35875.ED

Hansis, M. L., \& Hansis, D. E. (1999). Der ärztliche Behandlungsfehler. Verbessern statt streiten. Ecomed, Landsberg.

Hayden, J. A., van Tulder, M. W., Malmivaara, A., et al. (2005). Exercise therapy for treatment of non-specific low back pain. Cochrane Database Syst Rev, (3), CD000335. http://dx.doi.org/10.1177/0269215508097856

Hindle, D. (1997). Clinical pathways: a serious business. Health Management Bulletin, (1), 1-34.

Hommel, A., Ulander, K., Bjorkelund, K., et al. (2008). Influence of optimised treatment of people with hip fracture on time to operation, length of hospital stay, reoperations and mortality within 1 year. Injury, 39 (10), 1164-74. http://dx.doi.org/10.1016/j.injury.2008.01.048

Ishiguro, S., Yamamoto, S., Fujita, S., et al. (2008). Effect of a clinical pathway after laparoscopic surgery for colorectal cancer. Hepatogastroenterology, 55 (85), 1315-9.

Kohlmann, T., \& Raspe, H. H. (1996). Der Funktionsfragebogen Hannover zur alltagsnahen Diagnostik der Funktionsbeeinträchtigung durch Rückenschmerzen (FFbH-R). Rehabilitation, 35, I-VIII.

McWilliams, L. A., Cox, B. J., \& Enns M. W. (2003). Mood and anxiety disorders associated with chronic pain: an examination in a nationally representative sample. Pain, 106, 127-33. http://dx.doi.org/10.1016/S0304-3959(03) 00301-4

Prevoo, M. L., van't Hof, M. A., Kuper, H. H., et al. (1995). Modified disease activity scores that include twenty-eight-joint counts development and validation in a prospective longitudinal study of patients with rheumatoid arthritis. Arthritis Rheum, 38, 44-8. http://dx.doi.org/10.1002/art.1780380107

Roeder, N., Hoppenheit, C., Wolter, B., et al. (2007). Einführung eines softwareunterstützten integrierten und ganzheitlichen Risikomanagements im Universitätsklinikum Münster. Das Krankenhaus, (5), 429-437.

Romeyke, T. (2009). Von Minimieren und Maximieren. Risikomanagement und Qualitätssicherung: Grundlage für moderne und leistungsstarke Klinik. In: Qualitätsmanagement im Krankenhaus, 10, 6-7.

Rook, D. (1998). Cardiac surgery pathway cuts postoperative intubation time in half. Hosp Case Manag, 6, 9-12.

Schlüter, L., Roeder, N., \& Schaff, C. (2006). Behandlungspfade in der Kinder- und Jugendpsychiatrie. Von der Kooperation über die Vernetzung zur Integrierten Versorgung. Münster.

Schwarzbach, M., Bönninghoff, R., Harrer, K., et al. (2010). Effects of a clinical pathway on quality of care in kidney transplantation: a non-randomized clinical trial. Langenbeck's archives of surgery, 395 (1), 11-17. http://dx.doi.org/10.1007/s00423-009-0551-3

Sexton-Radek, K. (1999). Interplay of art making practices and migraine headache pain experience. Headache Quart: Curr Treat \& Res, 10 (4), 287-91. http://dx.doi.org/10.1258/jrsm.95.8.417

Tan, X., Yowler, C. J., Super, D. M., et al. (2010). The efficacy of music therapy protocols for decreasing pain, anxiety, and muscle tension levels during burn dressing changes: a prospective randomized crossover trial. J Burn Care Res, 31 (4), 590-7. 
Thomas, E. J., Studdert, D. M., Burstin, H. R., et al. (2000). Incidence and Types of adverse events and negligent care in Utah and Colorado. Med Care, 38 (3), 261-271.

Valim, V., Oliveira, L., Suda, A., et al. (2003). Aerobic fitness effects in fibromyalgia. J Rheumatol, 30 (5), 1060-1069.

Velasco, F. T., Ko, W., Rosengart, T., et al. (1996). Cost containment in cardiac surgery: results with a critical pathway for coronary bypass surgery at the New York Hospital-Cornell Medical Center. Best practices and benchmarking in healthcare, 1, 21-28.

Verdú, A., Maestre, A., López, P., et al. (2009). Clinical pathways as a healthcare tool: design, implementation and assessment of a clinical pathway for lower-extremity deep venous thrombosis. Quality \& Safety in Health Care, 18 (4), 314-20. http://dx.doi.org/10.1136/qshc.2007.023218

Vincent, C., Neale, G., \& Woloshynowych, M. (2001). Adverse Events in British Hospitals. British Medical Journal, 322, 517-519. http://dx.doi.org/10.1136/bmj.322.7285.517

Weingart, S. N., Wilson, R. M., Gibberd, R. W., et al. (2000). Education and debate. Epidemiology of medical error. British Medical Journal, 320, 774-777. http://dx.doi.org/10.1136/bmj.320.7237.774

Williams, R. M., Westmorland, M. G., Lin, C. A., et al. (2007). Effectiveness of workplace rehabilitation interventions in the treatment of work-related low back pain: a systematic review. Disabil Rehabil, 29 (8), 607-24.

Winkelmann, C., \& Schreiber, T. U. (1997). Die visuelle Analogskala (VAS) zur Schmerzmessung in der Physiotherapie. Zeitschrift für Physiotherapeuten, 49 (11), 1856-1866.

\section{Patient with chronic pain condition}

Manifest or threatened impairment of quality of life and/or capability

\begin{tabular}{|c|}
\hline $\begin{array}{c}\text { Failure of previous unimodal pain } \\
\text { therapy, a pain-relatedsurgical } \\
\text { intervention, or withdrawal treatment }\end{array}$ \\
\hline Exis ting medication addiction \\
or medication abuse
\end{tabular}

Fulfilment of at least 3 criteria to receive a multimodal pain therapy

Source: own representation adter O PS 8-918 (2010)

Figure 1. Pathway entry criteria for multimodal pain therapy (OPS 8-918) 


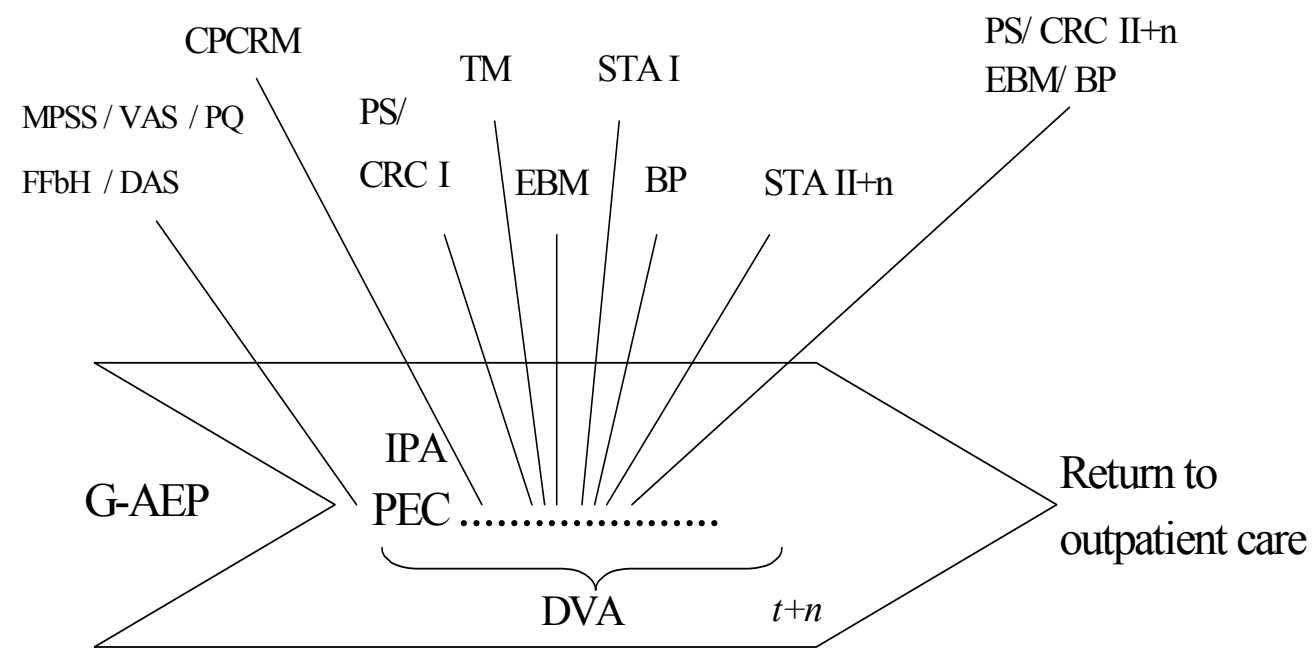

\section{Admission Management core process Outcome diagnostics and therapy}

PEC: Pathway Entry Criteria (complex treatment) CPCRM:Checklist for Pain Clinical Risk Management STA: Standardised Therapeutic Assessment (targeted therapy, evaluation of treatment goals)

G-AEP: German appropriate evaluation protocol

MPSS: Mainz Pain Staging System

VAS: Visual Analogue Scale

$\begin{array}{ll}\text { FFbH: Hannover Questionnaire } & \text { PQ: Pain questionnaire } \\ \text { DAS: Disease Activity Score } & \text { IPA: Interdis. Pain Anamnesis } \\ \text { DVA: Documentation and Variance Analysis } & \\ \text { TM: Team Meeting (interdisciplinar, in the early) } & \\ \text { PS/ CRC: Patient Status / Care-Related Comorbidities } & \\ \text { EBM: Evidence Based Medicine } & \\ \text { BP: Best Practice } & \end{array}$

Figure 2. Clinical Pathway: overview pain therapy

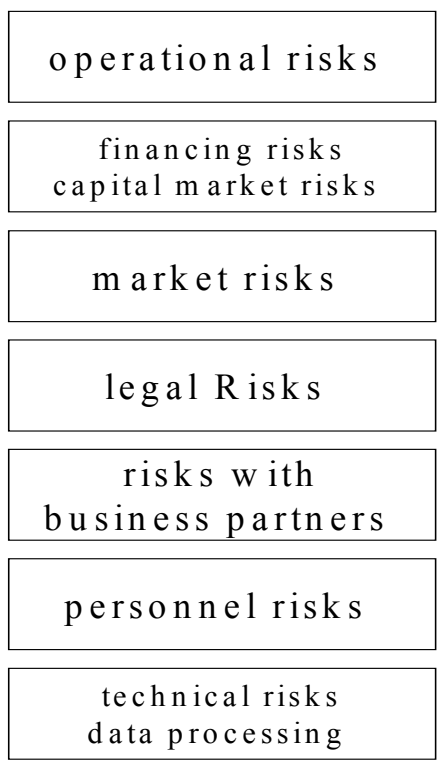

Delay in case statements

$\mathrm{M}$ aintenance of the medical establishment

Tightening in the lending

Access to and use of funding

Decrease in market power

Intensification of competition

Statutory requirements

Changes in laws

Contractual arrangements

Rabat contracts for elective hospital services

Training / qualifications, lack of doctors

Professionalism / core competencies, staff turnover

Privacy violations

Incorrect administration system $\mathrm{s} / \mathrm{softw}$ are

Figure 3. Risks in the hospital at the organizational level 


\begin{tabular}{|c|c|c|}
\hline & & \\
\hline stress incontinence & NB9.3 & \\
\hline reflexincontinence & N39.40 & \\
\hline overflowincontinence & NB9.41 & \\
\hline urge incortinence & NB9.42 & \\
\hline other specified urinary incontinence & N39.48 & \\
\hline uninary retertion & $\mathrm{R} 33$ & \\
\hline hematuria & $\mathrm{R} 31$ & \\
\hline persistent proteinura & NB9.1 & \\
\hline polyura & R35 & \\
\hline anuia and oliguia & R34 & \\
\hline fecal incontinence (dinical significance) & $\mathrm{R} 15$ & \\
\hline constipation & K59.0 & \\
\hline nausea and vomiting & $\mathrm{R} 11$ & \\
\hline vomiting blood & K920 & \\
\hline melaena, intestinal bleeding & K921 & \\
\hline gastrointestinal hemornhage (stomachor & E K92.2 & \\
\hline changes fecal (paint, slime, quantity, occult & R19.5 & \\
\hline functional dianhea & K59.1 & \\
\hline \multirow[t]{2}{*}{ psychogenic intestinal disorder } & F45.32 & \\
\hline & \multicolumn{2}{|c|}{ Confirmation of Pyysican } \\
\hline Dianhea: toxsic & K521 & \\
\hline Dianhea: infectious & A09 & \\
\hline Dianhea: non toxic & K529 & \\
\hline Dianhoea: by radiation exposure & K520 & \\
\hline Dianhoea: allergic and alimentary & K522 & \\
\hline presence of a tracheostomy & 203.0 & \\
\hline care of a tracheostomy & 243.0 & \\
\hline presence of PEG, gastrostomy & 293.1 & \\
\hline supplyPEG, gastrostomy & Z43.1 & \\
\hline presence of anileostomy & $Z 93.2$ & \\
\hline supply of anileostomy & $Z 43.2$ & \\
\hline presence of a colostomy & 293.3 & \\
\hline supply of a colostomy & Z43.3 & \\
\hline presence of a Zystostomas & $Z 93.5$ & \\
\hline supply of a Zystostomas & $Z 43.5$ & \\
\hline presence of a urostomy & $Z 93.6$ & \\
\hline supply of a urostomy & $Z 43.6$ & \\
\hline
\end{tabular}

\begin{tabular}{|c|c|c|}
\hline food intake & Confirmat & tition of the physician \\
\hline cachexia(BM below15 or 17) & R64 & \\
\hline obesity (BM 30 to less than 35) & 666.00 & \\
\hline obesity(BM 35 to 40$)$ & $E 66.01$ & \\
\hline dysphagia with supenvision, food intake & R13.0 & \\
\hline dysphagia in absaugpflichtigemtracheostomy & $\mathbf{R} 13.1$ & \\
\hline other swallowing & R13.9 & \\
\hline oral thrush & B37.0 & \\
\hline excessive thirst & R63.2 & \\
\hline improper diet and nutrition problems & R63.3 & \\
\hline flatulence and related conditions (belching, bloating, flatulence) & $\mathrm{R} 14$ & \\
\hline abnomal weight loss & R63.4 & \\
\hline Disorders / age and behavioral & Confirmat & tion of the physician \\
\hline senility / old age (do not code with dementia) & R54 & \\
\hline confusion, disorientation (not dementia) & RA10 & \\
\hline dementia (not with senility) & F03 & \\
\hline flaccid hemiplegia & G810 & \\
\hline spastic hemiplegia & G811 & \\
\hline paralysis of one leg & G83.1 & \\
\hline paralysis of anam & G 83.2 & \\
\hline dizziness and giddiness & R42 & \\
\hline restlessness and agitation & R45.1 & \\
\hline aphasia and dysphasia & R47.0 & \\
\hline anarthria and dysarthria & RA7.1 & \\
\hline blindness inone eye & H54.4 & \\
\hline bilateral visual impaiment & 154.2 & \\
\hline verystrong visual impaiment & H54.7 & \\
\hline blindness inbotheyes & 154.0 & \\
\hline blinheit one eye, impaired visionin other eye & H54.1 & \\
\hline amblyopiainone eye & †4.5 & \\
\hline numbness & H919 & \\
\hline tendency to fall (the elderly or the obscure disease states) & R29.6 & \\
\hline difficultyinwalking & R26.2 & \\
\hline Imitabilityand anger & R45.4 & \\
\hline Sonstiges & & Confirmation of the \\
\hline Decubitus first Degree (circumscribed erythema with intact skin) & L89.1- & \\
\hline Decubitussecond Degree (skin defect) & L89.2- & \\
\hline Decubitusthird Degree (deep skin defect) & L89.3. & \\
\hline Decubitus fourth Degree (deep skin defect with bone involvement) & L89.4 & \\
\hline Therapy with warfarin(aurentty) & 2921 & \\
\hline
\end{tabular}

Figure 4. Performance record sheet of care: care-related comorbidities 
- Completeness of the history of pain

- Coordination of medical and nursing history

- Completeness of information on pain diagnostic risks

- specialist medical verification of the results of the initial diagnostic

- Completeness of information on treatment-related risks

- Definition of all risks associated with treatment-specific applications of drugs can occur

- Completeness of medical and nursing documentation

- Implementation and documentation of the results of interdisciplinary therapeutic assessments

- Completeness of the clinical pathway variance analysis

- Ensure the completeness of technical information for training introduction of an outpatient unimodal pain management

- Compliance with the requirements for internal and external quality assurance

Figure 5. Checklist for Pain Clinical Risk Management

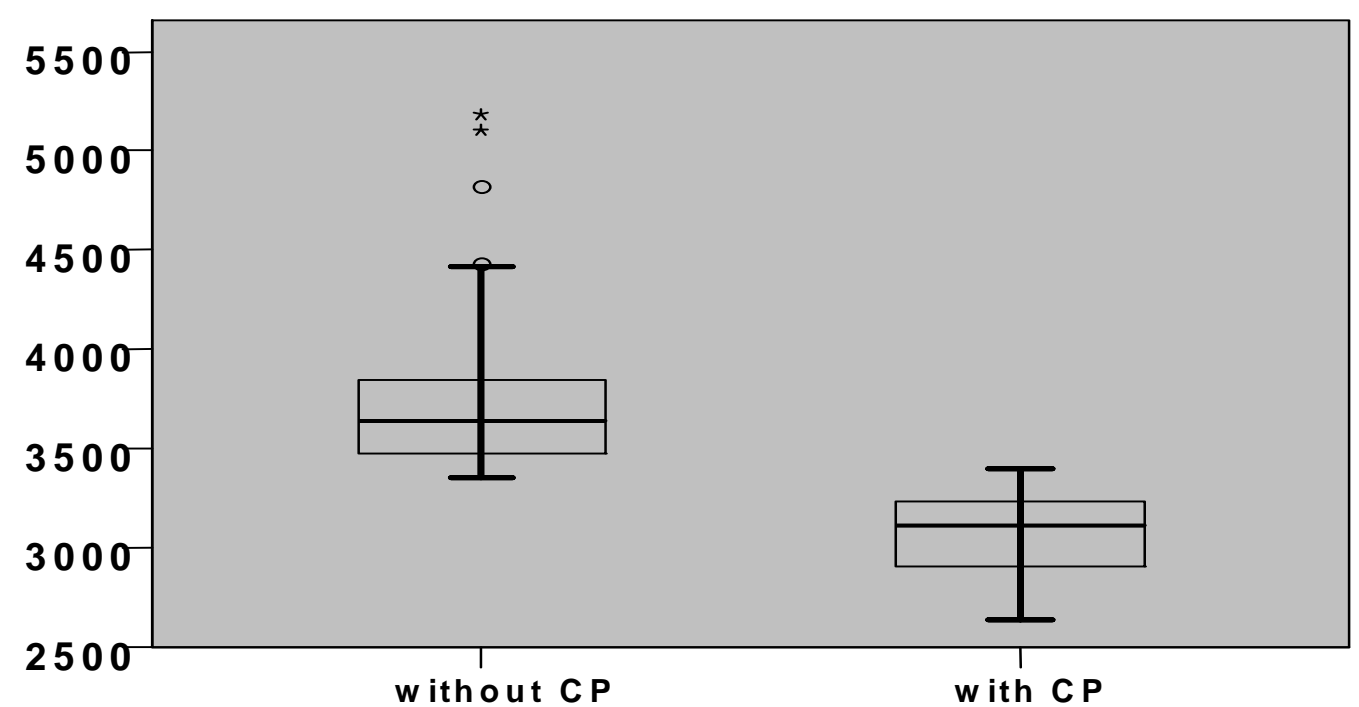

Figure 6a. Total cost for patients with vs. without $\mathrm{CP}$ in $\leftarrow(\mathrm{A} €$

\begin{tabular}{|l|c|r|r|r|r|}
\hline & Mean & $\begin{array}{c}\text { Standard } \\
\text { deviation }\end{array}$ & $\begin{array}{c}\text { Standard } \\
\text { error of the } \\
\text { mean }\end{array}$ & Median & N \\
\hline without CP & 3774.42 & 460.483 & 76.747 & 3642.50 & 36 \\
with CP & 3085.55 & 212.361 & 39.434 & 3114.00 & 29 \\
total & 3467.08 & 504.759 & 62.608 & 3420.00 & 65 \\
\hline
\end{tabular}

Figure $6 \mathrm{~b}$. Total cost for patients with vs. without $\mathrm{CP}$ in $€$ 